\title{
Progress towards the replacement of the rabbit blood sugar bioidentity assay by an in vitro test for batch release of insulins in quality control
}

The United States Pharmacopeia (USP) mandates an animal based assay in rabbits in its Chapter " $<121>$ Insulin Assays" (USP, 2015) for the potency evaluation (biological activity) of insulin and insulin analogs to be imported to the US. The test is based on the concentration dependent blood glucose lowering effect of insulin in rabbits and is included in the quality specification for insulins for the US market. It requires 8-24 animals per batch tested.

The European Pharmacopeia does not require such an in vivo bioidentity test. The European Medicines Agency (EMA) recommends to marketing authorization holders to ensure compliance with the $3 \mathrm{Rs}$ methods described in the European Pharmacopoeia and points to the fact that the competent authorities for granting approval of animal testing will request the more animal friendly European Pharmacopoeia method to be used ${ }^{1}$.

Insulin glargine is the drug substance in drugs like Lantus ${ }^{\circledR}$ and Toujeo ${ }^{\circledR}$ that are produced by Sanofi in Frankfurt and exported to the US, amounting to more than 4 billion USD in $2015^{2}$.

In 2012, Sanofi started a project to validate an experimental in vitro test as an alternative to the rabbit bioidentity assay with two objectives: The first objective was to enable the export of drugs containing insulin glargine to the US without animal experiments and the second objective was to achieve the inclusion of the in vitro method as an alternative to the rabbit bioidentity assay in the USP for all insulins for the US market.

The in vitro bioidentity test was validated according to USP requirements with respect to specificity, precision, re- producibility and robustness and its results were compared with animal data. The validation data (Tennagels et al., 2017) were submitted to the Food and Drug Administration (FDA) in February 2015 and the test was accepted in June 2015. As of January 2016, the rabbit assay is no longer performed for the export of insulin glargine to the US. This decision resulted in a reduction of animal use by about 2,000 rabbits per year compared to previous years.

For this achievement Sanofi was granted the Animal Welfare Research Award 2016 of the German state of Hesse ${ }^{3}$. Meanwhile, the insulin lispro, another product of Sanofi exported to the US, has undergone the same process.

In parallel, Sanofi validated the in vitro test for a number of other insulins on the US market (Tennagels et al., 2017). The validation data, the test conditions and the cell line used (CHO-INSR_1284) were made available to the USP and FDA, who were able to validate the in vitro test in-house. Also, the cell line has been made publicly available through American Type Culture Collection (ATCC).

As a result of Sanofi's groundwork, USP recently published a document for comment in section "General Chapters, In-Process Revision: <121> Insulin Assays" (USP, 2017), stating "a new in vitro cell-based bioidentity test for Insulin Glargine and Insulin Lispro is added as an alternative approach to in vivo bioidentity test using rabbits. (...) The new test was validated and approved by the FDA for assuring potency of a particular manufacturer's approved products. In the future, USP plans to omit the rabbit method completely after multiple manufacturers have been able to demonstrate that the cell-based method is appropriate for all their insulin

\footnotetext{
Received August 9, 2017

doi: 10.14573/altex.1708091

1 http://www.ema.europa.eu/docs/en_GB/document_library/Scientific_guideline/2012/07/WC500130369.pdf

2 Sanofi Annual Report 2015. http://en.sanofi.com/Images/45889_Sanofi_20-F_2015_V2.pdf

$3 \mathrm{https} / / /$ tierschutz.hessen.de/sites/tierschutz.hessen.de/files/content-downloads/428\%20-\%201611\%20PM\%20

Hessischer\%20Tierschutzforschungspreis.pdf
} 
products. This is part of USP's ongoing effort to phase out animal-based assays in favor of modern in vitro testing."

Thus, Sanofi has reached both objectives: Insulin glarginecontaining drugs can be exported to the US without the need to perform the rabbit bioassay, and the in vitro bioidentity test for batch release of insulins has been added to the USP test guideline $<121>$ as an alternative to the rabbit blood sugar assay. Pharmaceutical companies producing insulins for the US market are no longer obliged to perform the rabbit assay and are encouraged by USP to use the in vitro test. The number of animals used for batch release of insulins could therefore drop considerably, since the in vitro test proved to have no disadvantages compared to the rabbit test with respect to specificity, precision, reproducibility and robustness (Tennagels et al., 2017).

\section{References}

Tennagels, N., Usener, D., Rueggeberg, S. et al. (2017). Stimuli to the Revision Process: A Proposed In Vitro Cell Based Bioassay to Include into the USP general chapter Insulin Assays
$<121>$. US Pharmacopoeial Forum 43(4). http://www.usppf. com/pf/pub/index.html

USP-US Pharmacopoiea (2015). Chapter $<121>$ Insulin Assays. http://www.usp.org/sites/default/files/usp_pdf/EN/gc_121_ insulin_assays_03012015.pdf

USP (2017). In-Process Revision: <121> Insulin Assays: "In Vitro Cell-Based Bioidentity Test for Insulin Glargine and Insulin Lispro" as additional method in the USP chapter $<121>$ Insulin Assays. US Pharmacopeial Forum 43(4). http://www. usppf.com/pf/pub/index.html

Rüdiger Hack, Sabrina Rueggeberg, Lea Schneider, Dirk Mayert, Norbert Tennagels, Stefan Welte, Birgit Niederhaus, Wilfried Arz, Dirk Usener, Götz Troschau, Johannes Meiwes and Jochen Maas

Sanofi-Aventis Deutschland GmbH, Industriepark Hoechst, 65926 Frankfurt, Germany e-mail: ruediger.hack@sanofi.com 